Supporting information

\title{
Birnessite-Type Manganese Oxide on Granular Activated Carbon for Formaldehyde Removal at Room Temperature
}

\author{
Jinge Li, Pengyi Zhang*, Jinlong Wang, Mingxiao Wang, \\ State Key Joint Laboratory of Environmental Simulation and Pollution Control, \\ School of Environment, Tsinghua University, Beijing 100084, China
}

${ }^{*}$ Corresponding author.

Pengyi Zhang

Tel: +86 10-62773720;

Fax: +86-10-62797760;

E-mail: zpy@tsinghua.edu.cn 


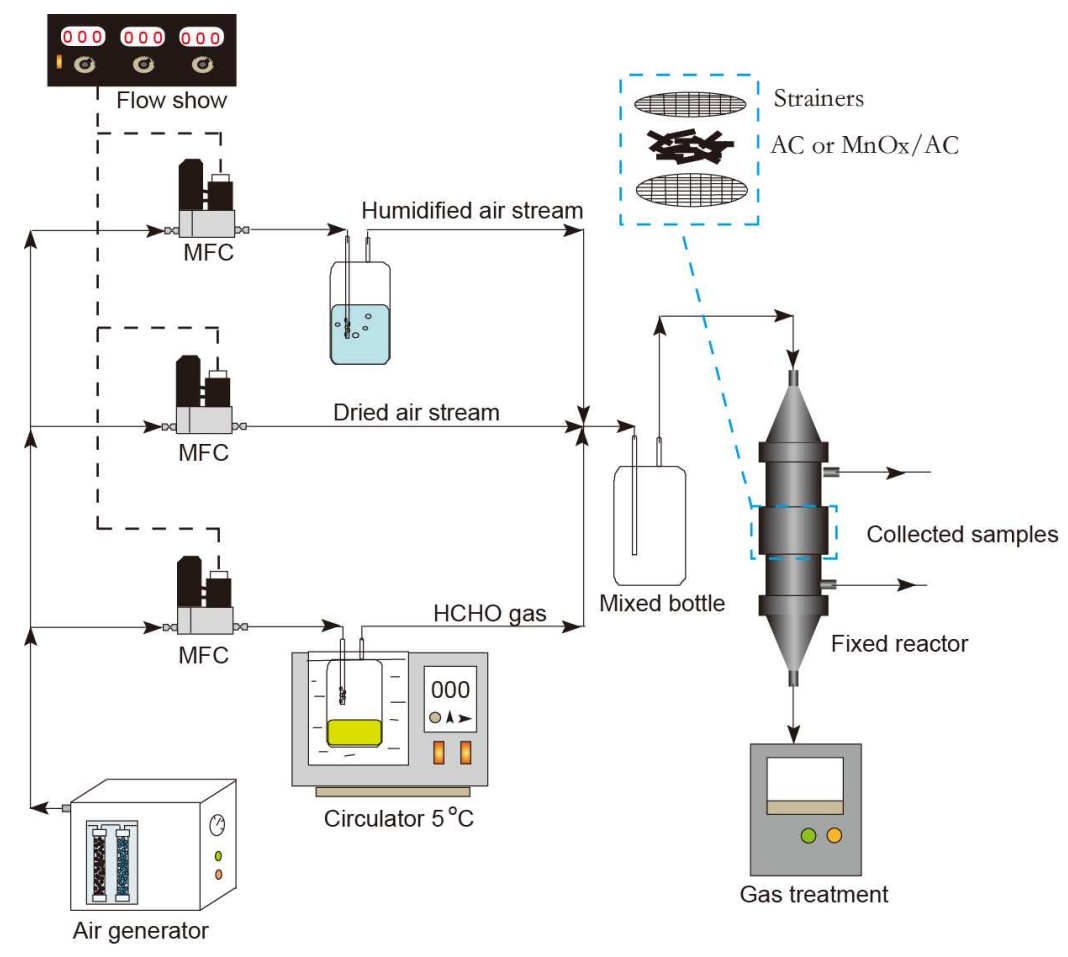

Figure S1. Schematic diagram of the experimental setup.

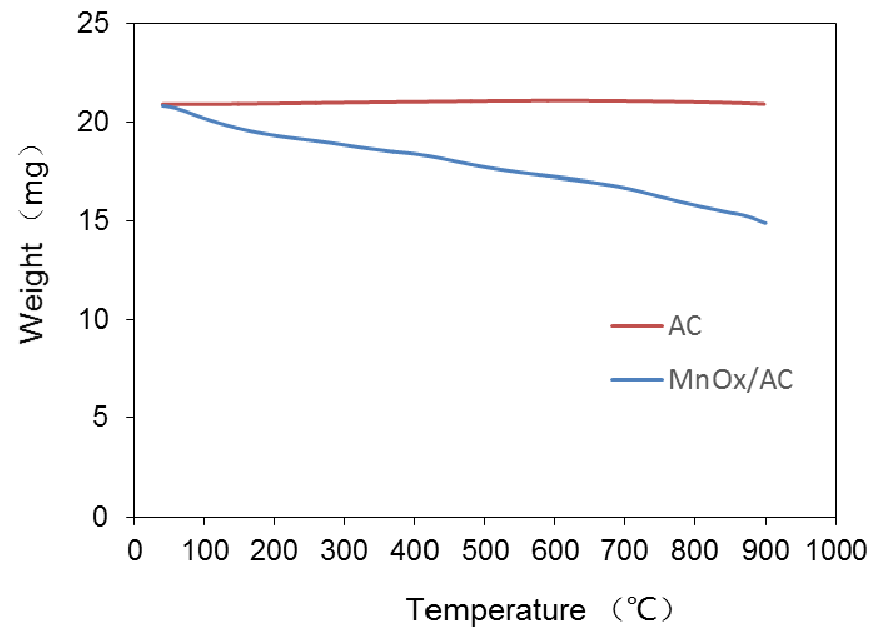

Figure S2. TGA plot for $\mathrm{MnO}_{\mathrm{x}} / \mathrm{AC}$ and $\mathrm{AC}$ in a $\mathrm{N}_{2}$ atmosphere from 40 to $900^{\circ} \mathrm{C}$ with a ramp of $10^{\circ} \mathrm{C} / \mathrm{min}$.

Growth of $\mathrm{MnO}_{\mathbf{x}}$ on the AC surface. According to the SEM results, the growing process of $\mathrm{MnO}_{\mathrm{x}}$ on the surface of $\mathrm{AC}$ was illustrated in Figure S3. The process can S2 
be divided into two stages via a nucleation-dissolution-recrystallization growth process. In the early stage, $\mathrm{KMnO}_{4}$ is reduced rapidly by $\mathrm{AC}$ to produce nanosheets of $\mathrm{MnO}_{\mathrm{x}}$ at room temperature. This involves the fast nucleation of amorphous nanosheets, followed by slow aggregation. Those nanosheets are metastable under their mother liquor and are gradually re-dissolved over the period of several hours. In the second stage, the nanosheets tend to assemble into microspheres.

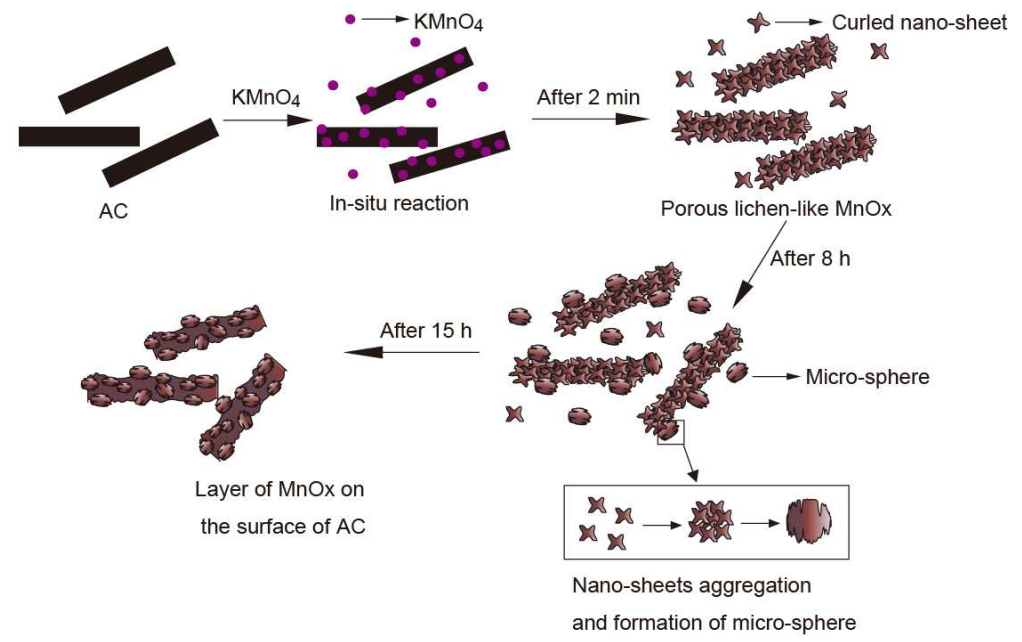

Figure S3. Schematic growing process of $\mathrm{MnOx}$ on the surface of AC.
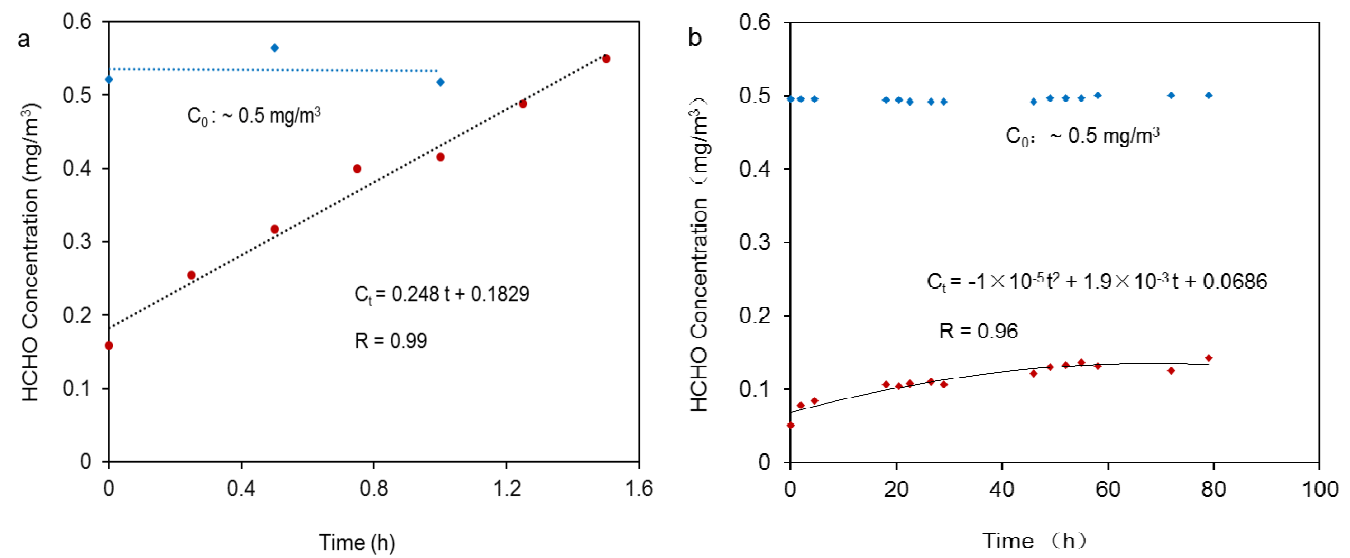

Figure S4 Time-dependence of $\mathrm{HCHO}$ by $\mathrm{AC}(\mathrm{a})$ and $\mathrm{MnO}_{\mathrm{x}} / \mathrm{AC}(\mathrm{b})$. 